\title{
Fragile X syndrome: causes, diagnosis, mechanisms, and therapeutics
}

\author{
Claudia Bagni, ${ }^{1,2,3}$ Flora Tassone, ${ }^{4,5}$ Giovanni Neri, ${ }^{6}$ and Randi Hagerman ${ }^{5,7}$
}

\begin{abstract}
${ }^{1}$ Katholieke Universiteit Leuven, Center for Human Genetics, Leuven, Belgium. ${ }^{2 V I B}$ Center for the Biology of Disease, Leuven, Belgium.
${ }^{3}$ Department of Biomedicine and Prevention, University of Rome "Tor Vergata," Rome, Italy.

${ }^{4}$ Department of Biochemistry and Molecular Medicine, UCD, School of Medicine, Davis, California, USA. ${ }^{5}$ UC Davis MIND Institute, UCD, Medical Center, Sacramento, California, USA. 6 Institute of Medical Genetics, Catholic University, Rome, Italy.

7Department of Pediatrics, UCD, Davis Medical Center, Sacramento, California, USA.
\end{abstract}

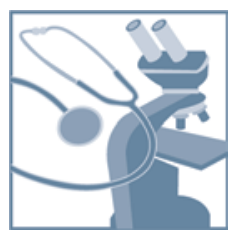

Fragile X syndrome (FXS) is the most frequent form of inherited intellectual disability and is also linked to other neurologic and psychiatric disorders. FXS is caused by a triplet expansion that inhibits expression of the FMR1 gene; the gene product, FMRP, regulates mRNA metabolism in the brain and thus controls the expression of key molecules involved in receptor signaling and spine morphology. While there is no definitive cure for FXS, the understanding of FMRP function has paved the way for rational treatment designs that could potentially reverse many of the neurobiological changes observed in FXS. Additionally, behavioral, pharmacological, and cognitive interventions can raise the quality of life for both patients and their families.

\section{Genetics of fragile $X$}

Fragile X syndrome (FXS), an X-linked condition first described by Martin and Bell (1), is the leading cause of inherited intellectual disability (ID). Estimates report that FXS affects approximately 1 in 2,500 to 5,000 men and 1 in 4,000 to 6,000 women $(2,3)$. FXS is caused by mutations in the FMR1 gene, which is located on the X chromosome and whose locus at Xq27.3 coincides with the folate-sensitive fragile site $(4,5)$. Cytogenetic methods (6) used in the past to diagnose FXS have been replaced by molecular diagnostic of FMR1 DNA using Southern blot analysis and, more recently, PCR.

Affected men display varying degrees of symptoms ranging from mild to severe. Due to compensation by the unaffected X chromosome, only one-third of female carriers with a full mutation (FM) have ID; the majority have normal IQ, although learning difficulties and emotional problems are common (7).

Identified in 1991 by positional cloning (8), the FMR1 gene is characterized by the presence of a polymorphic CGG triplet sequence in the $5^{\prime} \operatorname{UTR}(8,9)$. Expansion in this triplet sequence gives rise to FXS, which is the prototype of unstable triplet expansion disorders. The triplet variability defines four types of alleles (Figure 1). Normal alleles have a number of CGG repeats, ranging from 5 to 54 , with a mode of 30 . Premutation (PM) alleles have a number of CGG repeats, ranging from 55 to 200 . PM alleles are unstable and have a strong tendency to expand to FM alleles upon maternal transmission. Expansion from a PM to FM can occur with alleles as small as 56 CGGs (10). Alleles possessing between 45 and 54 CGG repeats, referred to as gray-zone or intermediate alleles, are proposed to be precursors of PM alleles, potentially due to paternal and maternal meiotic instability (11). The risk of a PM to FM transition depends on the CGG repeat size, such that the expansion risk is nearly $100 \%$ for alleles

Conflict of interest: Randi Hagerman has received grant support from Roche, Novartis, Seaside Therapeutics, Forest, and Curemark to carry out clinical trials for fragile $\mathrm{X}$ and/or ASD. She has also consulted with Novartis regarding clinical trials in fragile $\mathrm{X}$ syndrome. Giovanni Neri received grant support from Novartis for an in vitro study of AFQ056.

Citation for this article: J Clin Invest. 2012;122(12):4314-4322. doi:10.1172/JCI63141. of >99 CGG repeats (11). A recent study (12) showed that the number of AGG interruptions present in the CGG repeats correlates inversely with the risk of expansion to a FM in the next generation. The presence of AGG interruptions, in addition to the CGG length, may thus better define the risk for transmission from a maternal PM to FM in the offspring.

FMR1 silencing is the consequence of rather complex epigenetic modifications (13). In FXS, cytosines located approximately up to 1 -kb upstream of the CGG repeat sequences, including the FMR1 promoter, are methylated $(14,15)$. Normal alleles are also methylated in the FMR1 promoter region but not in close proximity to the CGG repeat, which seems to be a "boundary" in the normal allele that prevents methylation from spreading. This boundary is missing in FM alleles, and the cytosines upstream of the CGG repeat become methylated around the thirteenth week of embryonic development (16). As a consequence, gene transcription is inhibited, leading to the absence of its protein product FMRP (17). Of note, some alleles remain partially or even fully unmethylated (UFM), despite containing >200 CGG repeats, but the differences in methylation status are poorly understood.

In addition to altered methylation status, FXS alleles show deacetylation of histones $\mathrm{H} 3$ and $\mathrm{H} 4$, reduced methylation of lysine 4 (K4), and increased methylation of lysine 9 (K9) on histone H3 (18). These epigenetic changes promote a heterochromatic configuration that excludes the binding of specific transcription factors (19), thus turning gene expression off (20). The rare UFM alleles notably maintain a normal or higher FMR1 transcriptional activity, with reduced FMRP levels (21); acetylation of histones $\mathrm{H} 3$ and $\mathrm{H} 4$ and methylation of lysine 9 on H3 of UFM alleles are more similar to those of FM alleles, while the level of methylation of lysines 4 and 27 on $\mathrm{H} 3$ are more similar to that of normal alleles $(18,22)$.

\section{Clinical diagnosis of fragile $X$ in young and adult patients} Early diagnosis. A diagnosis of FXS is often made in young children of approximately 3 years of age (23), who show delayed or absent speech. Among the recurrent problems that may occur in children before 2 years of age are hypotonia, delayed motor milestones, hand flapping, 
Normal
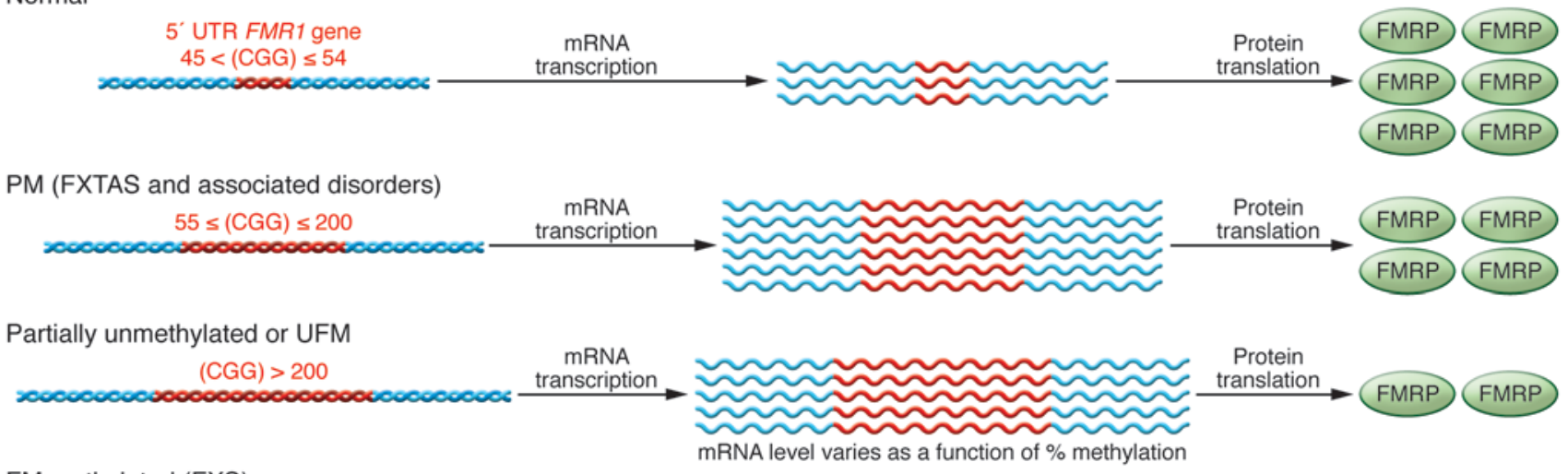

FM methylated (FXS)

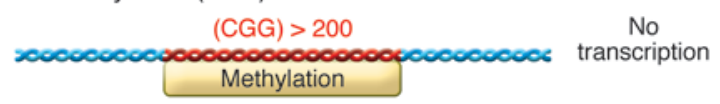

\section{Figure 1}

The four alleles of the human FMR1 gene. According to the degree of CGG triplet expansion and the level of FMR1 mRNA transcription and translation changes, four alleles are generated: normal, PM, UFM, and FM.

poor eye contact, frequent emesis and/or otitis media, and irritability. The behavior of boys with FXS typically includes attention deficit hyperactivity disorder (ADHD), with significant impulsivity and anxiety, as well as behaviors that include repetitive language, hand biting, hand stereotypies, rocking, and sometimes head banging $(24,25)$. These behaviors, combined with social and language deficits, often lead to a diagnosis of autism spectrum disorder (ASD) before the diagnosis of FXS is made. Approximately $30 \%$ of boys with FXS meet the diagnostic criteria for autism, and these children have the lowest developmental and adaptive behavior scores of those with FXS. A child with FXS is often described as hyperaroused; an imbalance of the excitatory and inhibitory synaptic pathways described in the "From RNA metabolism to synaptic receptor dysfunction" section may contribute to such a clinical phenotype. Studies on postmortem brains from patients with FM and lacking FMRP revealed a neuronal spine dysmorphogenesis (26).

After the proband is diagnosed with FXS, a subsequent cascade testing of family members will identify relatives with either the PM or FM. Since FXS is complex, consulting a genetic counselor to ensure correct interpretation of all positive fragile $\mathrm{X}$ test results is advisable, allowing the provision of appropriate clinical advice for those with PM or FM (27). Relatives may also be at risk of having children with ID and therefore should also be offered genetic counseling.

Other clinical observations in the family may reveal the FXS phenotype. Sometimes a family history of ID, ASD, neurological problems (such as tremor, ataxia, or dementia in one of the grandparents), or early menopause (before 40 years of age) will lead the clinician to diagnose FXS in the family. The neurological problems described above are associated with a recently identified neurodegenerative disorder seen in PM carriers, the fragile $\mathrm{X}$-associated tremor ataxia syndrome (FXTAS) (28). FXTAS (Figure 1) has been reported to affect approximately $46 \%$ of male and $17 \%$ of female adult carriers (28).

Over the last few years, insight into the spectrum of phenotypes in both the PM and the FM alleles has substantially increased. In PM carriers, shyness, anxiety, social deficits, and ADHD are some of the most common features observed, particularly in boys (29-31). In addition, fragile $\mathrm{X}$-associated primary ovarian insuf- ficiency (FXPOI), defined by the cessation of menses prior to the age of 40 , occurs in approximately $20 \%$ of women with PM (32).

Late diagnosis. A late diagnosis may occur for older patients who may have undergone genetic testing prior to the 1991 discovery of the FMR1 gene (8) or for patients that carry a mild form of the disease, showing atypical symptoms as often occurs for the UFM alleles. Occasionally, individuals with FXS were institutionalized in adolescence or adulthood, without a subsequent diagnostic study to find the cause of their ID. In addition, the majority of women with FM often do not have ID, and they are frequently diagnosed with FM following the diagnosis of FXS in their children.

\section{Screening for FXS alleles: early diagnosis}

The results of a pilot newborn screening (NBS) study for FXS in the United States, based on the screening of 11,217 newborns, indicated that the observed prevalence of a PM allele is 1:188 in females and 1:480 in males, while the prevalence of gray-zone alleles (45-54 CGG repeats) is 1:70 in females and 1:107 in males (33). PM prevalence was found to be different in various ethnic groups; it was higher in people of mixed European descent compared with that in African American and Hispanic people (for both males and females) and shows a higher incidence for PM compared with that in previous studies $(34,35)$. NBS for FMR1 mutations is not currently included in the NBS program, mainly because it may also identify FMR1 mutations that may not develop a severe FXS due to partial inactivation (UFM) as well as carriers that may develop FXTAS later in life. NBS has recently captured attention with the introduction of targeted treatments with encouraging results $(36,37)$ and the use of new PCR-based population screening approaches $(34,38-43)$. Of note, in a recent European study of 213 FXS prenatal diagnoses, $17.6 \%$ of those with a family history of unknown ID were found to be FXS carriers (44).

\section{Clinical crosstalk between fragile $X$ and autism}

The fragile $\mathrm{X}$ mutation is the most common single genetic cause of autism, occurring in $1 \%$ to $6 \%$ of boys with ASD (7). Individuals with ASD and FXS have a lower IQ and lower receptive and 


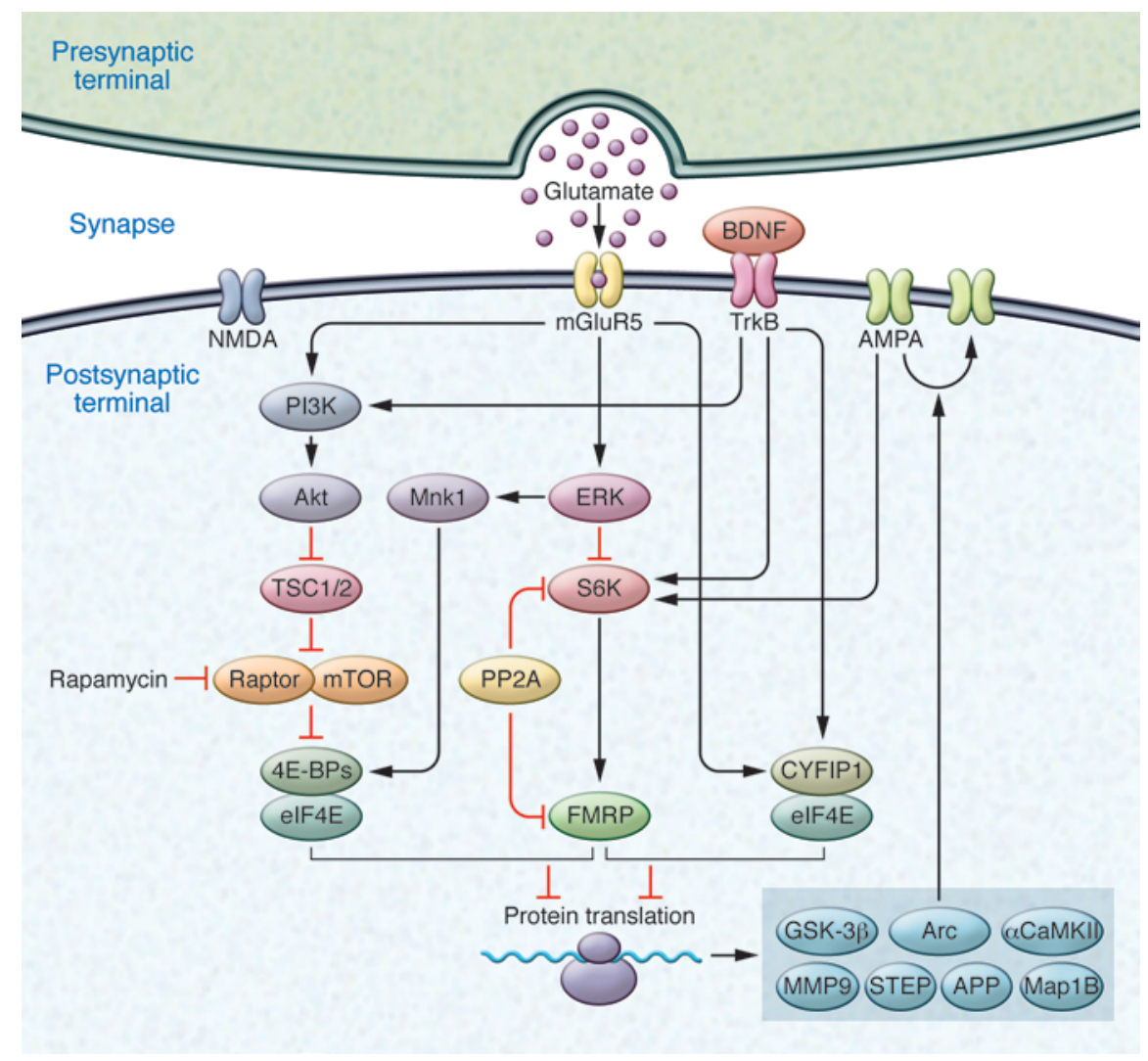

Figure 2

Effects of receptor signaling pathways on FMRP-mediated regulation at synapses. A complex cascade of molecules downstream of glutamate (NMDA, AMPA, mGluR5) and BDNF receptors modulates FMRP activity at synapses. FMRP is affected by mTOR and Mnk1 signaling pathways (89) that regulate phosphorylation of general elF4E-binding proteins and consequently protein synthesis. FMRP can be phosphorylated by S6 kinase (S6K) (72) or dephosphorylated by protein phosphatase 2A (PP2A) (137). The phosphorylation status affects its RNA-binding properties as well as its translational regulation. Mechanistically, FMRP has been shown to interact with the initiation factor elF4E and regulate translational through the specific elF4E-binding protein CYFIP1 (52). Further studies are required to verify whether FMRP also binds general elF4E-BPs and whether these signaling pathways affect the FMRP-CYFIP1 complex as well. FMRP may also affect translational elongation (58). In absence of FMRP, the upstream kinase phosphatidylinositol 3-kinase (PI3K) is upregulated, leading to the increased mTOR phosphorylation and activity observed in patients with FXS as well as in the Fmr1 KO mouse $(87,89)$, culminating in an increased protein synthesis. Similar and possibly convergent effects are due to an upregulation of ERK $(72,87-89)$ and TrkB (85) signaling. In absence of FMRP, there is an increase of a subset of locally synthesized proteins (Arc, Map1B, $\alpha$ CAMKII, postsynaptic density-95 [PSD-95], MMP9, GSK-3 $\beta$, among others). The increased Arc level contributes to an increased AMPA internalization and reduced AMPA in the membrane. At the same time, Arc, Map1B, PSD-95, and other dysregulated proteins involved in cytoskeleton scaffolding and remodeling may contribute to the FXS dysmorphic spine as well.

expressive language abilities compared with individuals having FXS alone (45). Most individuals with FXS and ASD have, in addition to the described hand mannerisms and speech problems, significant deficits in social interaction and communication persistently over time (46). Children with FXS and seizures (47) as well as additional medical problems that affect the CNS, such as birth asphyxia or additional gene mutations, are at greater risk of having autism in addition to FXS (48). Very recent studies on patients with FXS and FXS plus ASD supported the endophenotype of social withdrawal via decrease of cortico-cortical connectivity and organization (49). Thus initiating established behavioral interventions for patients with FXS and ASD is important, including Applied Behavioral Analysis and the Early Start Denver Model $(50,51)$, alongside the "symptomatic" pharmacological approaches discussed below.

While the cause(s) of ASD in some individuals with FXS is still not known, human genetic studies as well as those that use mouse models have examined the molecular link between FXS and ASD.
Recent evidence indicates that dysregulation and or mutations of FMRP-interacting proteins, such as the cytoplasmic FMRP-interacting protein 1 (CYFIP1) (52-55), eukaryotic initiation factor 4 (eIF4E) $(56,57)$, and a subset of FMRP mRNA targets (58), may contribute to the ASD phenotype observed in FXS.

\section{From RNA metabolism to synaptic receptor dysfunction}

FMRP is an RNA-binding protein, and, despite its clear shuttling from the nucleus to the cytoplasm $(59,60)$, only the cytoplasmic function of FMRP has been well characterized. FMRP forms large cytoplasmic ribonucleoparticles containing several other proteins (61) and RNAs $(62,63)$. FMRP has been detected in P bodies and stress granules as well, where it forms translationally silent preinitiation complexes (64) (Figure 2). FMRP regulates stability, subcellular transport, and translation of neuronal mRNAs encoding for proteins involved the in synaptic structure and function $(58,65-67)$. The best-characterized function of FMRP, based on studies of the Fmr1 KO mouse model (68), 
A

\section{FM methylated (FXS)}

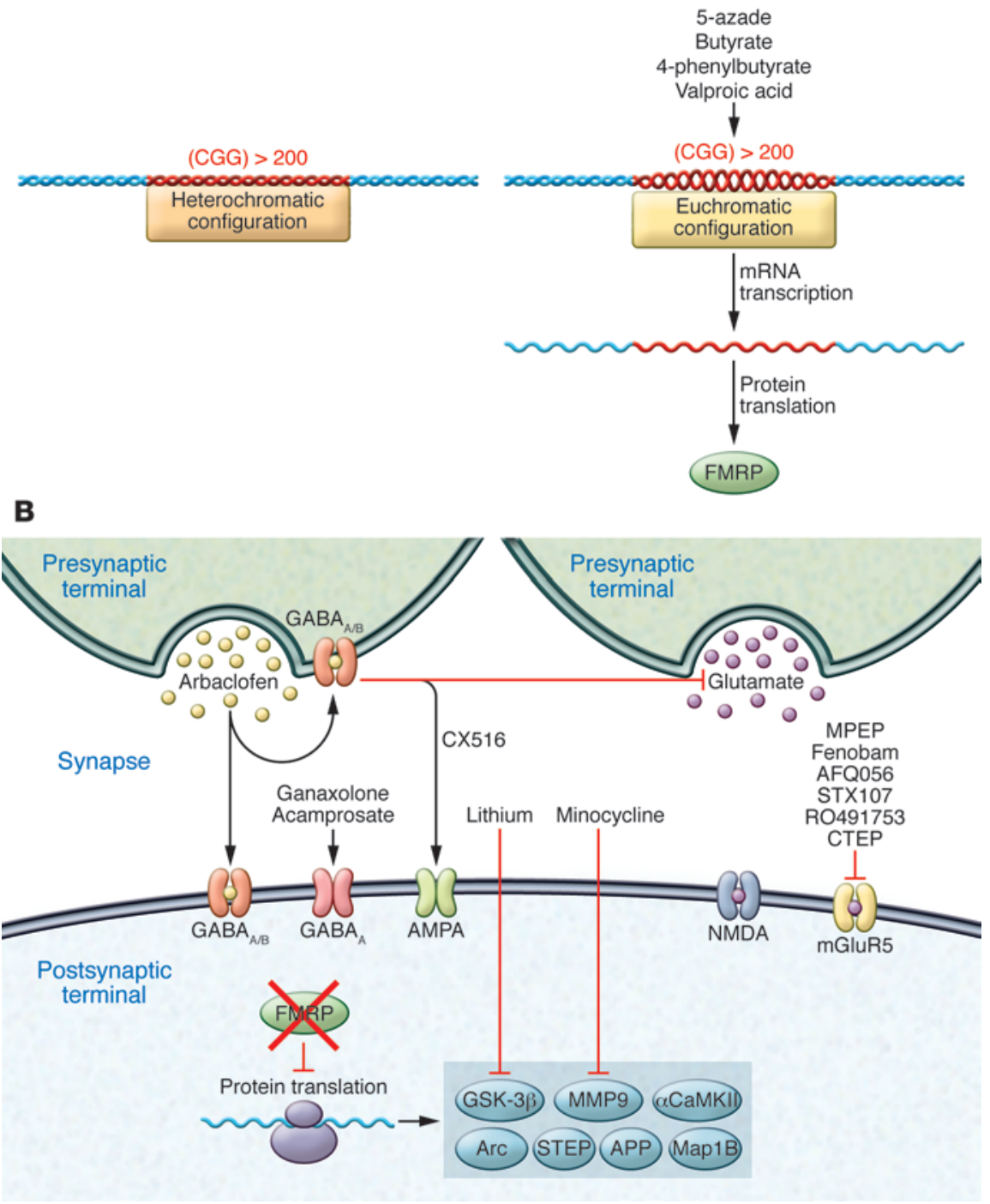

\section{Figure 3}

Toward a therapy for FXS. (A) Epigeneticmodifying compounds that may reactivate FMR1 gene expression. (B) Compounds used in clinical trials and affecting dysregulated molecules and pathways are shown. Lack of FMRP leads to a dysregulated synthesis of molecules with key functions at synapses, such as increased levels of Arc, aCAMKII, MMP9, GSK-3 $\beta$, mGluR, and NMDA and decreased GABA and AMPA receptor activity. Arrows and inhibition symbols do not necessarily represent direct interactions.

metabotropic glutamate receptors (mGluRs) (78), 2-amino-3-(5-methyl-3-oxo-1,2-oxazol-4-yl) propanoic acid (AMPA) receptors (79), $\gamma$-aminobutyric acid (GABA) receptors (76, 80, 81), $N$-methyl-D-aspartate (NMDA) receptors (82-84), and the tyrosine kinase or BDNF/NT-3 growth factor (TrkB) receptors (85). Upon receptor activation, the FMRPmediated translational block is released, possibly due to changes (86) in its phosphorylation status, and protein synthesis can ensue. In the absence of FMRP, there is an increase in the synthesis of several proteins involved in cytoskeleton remodeling and receptor internalization (i.e., Arc) (Figure 2) as well as reduction of other proteins due to a reduced stability of their mRNAs (i.e., GABA-R subunits). Elevation of the glutamate receptors mGluR1 and mGluR5 and the reduced insertion of AMPA receptors into the postsynaptic membrane are two of the central mechanics of impaired synaptic plasticity in FXS: such a dysregulated signaling is the basis of mGluR theory (75). This receptor unbalance results in enhanced mGluR-long-term depression (mGluR-LTD), the most commonly studied forms of hippocampal synaptic plasticity.

is as a translational repressor (Figure 2), and the absence of FMRP thus leads to increased protein synthesis $(52,69-74)$. High-throughput screenings supported by accompanying small scale studies have revealed that a wide array of neuronal mRNAs, with a large proportion encoding for presynaptic and postsynaptic proteins, is deregulated in the absence of FMRP, suggesting that concerted alteration of many proteins contributes to the FXS phenotype (62).

Spine dysmorphogenesis represents the quantitative measure widely adopted in the mouse model for FXS to understand cellular and network changes in the absence of FMRP (61). Furthermore, extensive electrophysiological studies in the Fmr1 KO mouse model indicated an excitation/inhibition (glutamate/GABA; see below) imbalance (75-77). Because the mouse model recapitulates morphological changes and behavioral deficits seen in human patients, these molecular insights have led clinicians to design targeted treatments (see below).

Over the last five years, there have been major advances in our understanding of the signaling pathways acting on FMRP as well as regulated by FMRP (Figure 2). FMRP activity is regulated in response to
The molecular signaling pathways orchestrating protein synthesis, spine shape, and synaptic plasticity, such as mTOR and ERK (Figure 2), are also impaired in FXS (72, 87-89), possibly because some FMRP target mRNAs encode members of second messenger cascades converging on $\operatorname{ERK}(88,89)$.

\section{Amelioration of the phenotype in the mouse model: a genetic approach}

Several laboratories have successfully attempted to genetically rescue the FXS phenotype, with varying degrees of efficacy. mGluRs (mGluR1 and mGluR5) are members of the G proteincoupled receptor family that influence synaptic plasticity-regulating processes, such as learning, memory, and anxiety as well as perception of pain. Activation of mGluRs leads to LTD of the post-synapses that is local protein synthesis dependent. Absence of FMRP leads to an increase of local protein synthesis (Figures 2 and 3), initially shown for the activity-regulated cytoskeleton protein (Arc), microtubule-associated protein 1B (Map1B), and alpha $\mathrm{Ca}^{2+} /$ calmodulin-dependent kinase II ( $\alpha$ CaMKII) proteins (69). 
As mentioned, mGluR-LTD is enhanced in mice lacking FMRP (78). These findings suggest that downregulation of mGluRs may be a potential target for FXS therapeutic interventions. Elevated LTD causes loss of AMPA and NMDA receptors from the surface of postsynaptic structures, possibly affecting the elongation of dendritic spines $(75,79)$. The mGluR theory was initially tested by crossing mice heterozygous for the mGluR5 encoding gene $\left(\mathrm{Grm5}^{+/-}\right.$mice) with Fmr1 KO mice. The resulting 50\% reduction in mGluR5 protein levels in the offspring led to the correction of typical FXS phenotypic features, including spine dysmorphogenesis and audiogenic seizures, and restored mGluR-LTD (90).

Interestingly, the amyloid $\beta$-protein precursor $(\mathrm{A} \beta \mathrm{PP})$ is upregulated in the FXS mouse model $(52,73)$. Genetic reduction of A $\beta P P$ in Fmr1 KO mice rescues characteristic FXS phenotypes, such as audiogenic seizures, the ratio of mature versus immature dendritic spines, and mGluR-LTD (91). Future studies are required to identify the mechanism of A $\beta$ PP action at FXS synapses.

In another study, mice heterozygous for the tuberous sclerosis complex 2 (Tsc2 $2^{+/-}$mice), a GTPase-activating protein known to inhibit the kinase mTOR (Figure 2), were crossed with the Fmr1 $\mathrm{KO}$ mice. Also in this case, the FXS phenotype was rescued with normalization of neuronal protein synthesis and electrophysiological responses (92). Because both mouse models have upregulated mTOR pathway activity, the authors propose that normal synaptic plasticity and cognition occur within an optimal range of mGluRmediated protein synthesis, such that deviations in either direction can lead to shared behavioral impairments.

FMRP has been shown to interact with the p21-activated kinase (PAK), an enzyme known to play a critical role in actin polymerization and dendritic spine morphogenesis. Expression of a dominant-negative mutant of PAK in the forebrain of Fmr1 KO mice led to an improvement of several behavioral abnormalities, such as impaired locomotor activity, stereotypical anxiety, and trace fear conditioning, suggesting that the PAK signaling pathway could also represent a bona fide site for therapeutic intervention (93).

Recently, the striatal enriched protein tyrosine phosphatase (STEP) has been shown to be upregulated in FXS, and genetic reduction of STEP diminished seizures and restored selected social and nonsocial anxiety-related behaviors in the Fmr1 KO mice (94). Because STEP acts on at least three molecules (ERK1/2, NMDA, and AMPA) affected in FXS, strategies to inhibit STEP activity may be considered for treating patients with FXS.

\section{Therapeutic approaches to FXS}

During the past decade, intense effort has been focused on the development of specific FXS treatments that might lead to eventual cure. Two possible approaches are presently being considered for a substantial treatment of FXS: (a) reactivation of the affected gene and (b) compensating for the lack of FMRP.

Epigenetic modulators. The strategy of restoring FMR1 gene activity, which is based on the presence of the intact FMR 1 coding sequence, targets potentially reversible epigenetic changes, primarily DNA methylation. The first compound tested on cells derived from patients with FXS was the drug 5-aza-deoxycytidine (5-azadC, a methyltransferase inhibitor; Figure 3A), which restored transcription and translation of the FMR1 gene (95). Furthermore, treatment with histone deacetylase inhibitors (TSA, butyrate, and 4-phenylbutyrate) potentiated the effect of 5-azadC (96). Reactivation was accompanied not only by DNA demethylation but also by changes in the epigenetic code of histones $\mathrm{H} 3$ and
H4 (97). As result of these changes, the inactive, methylated FM allele became similar to the active UFM allele. Even though the cause of this reduction in methylation is unknown, converting a carrier of a methylated FM allele into a carrier of an UFM allele, by pharmacological intervention, appears to be a logical approach. While the action of 5-azadC appears to be specific in the context of the FMR1 gene, as shown by its lack of effect on the methylated sequence upstream of the FMR1 boundary (G. Neri, unpublished observations), effects on other methylated genes cannot be excluded. Furthermore, 5 -azadC cannot be readily used in vivo because of safety issues (induction of apoptosis). Moreover, it is presumed to be effective only on dividing cells, which excludes postmitotic neurons. Acetyl-L-carnitine (Nicetile, a natural compound improving cell metabolism), shown to inhibit cytogenetic expression of the fragile $\mathrm{X}$ site in patient-derived cultured lymphocytes (98), was administered to boys with FXS (99). A significant amelioration of the hyperactivity and adaptive behavior of drug-treated boys (compared with those treated with placebo) was observed; however, the methylation state of FMR1 did not change, and the expression of the gene did not increase (100). The third tested compound is valproic acid (101), which is already known as a reactivator of silenced genes (102) that appeared to be a weak reactivator of FM (103). On a small, open-label trial of 10 boys with FXS, essentially meant to be a safety trial, treatment with valproic acid resulted in a general improvement in hyperactivity and attention deficit (104).

Glutamatergic system. Several receptor-signaling pathways (Figure 2) are impaired in FXS. The reduced functional AMPA receptor in the FXS mouse model has led clinicians to use, in an open trial with FXS patients, a positive allosteric modulator of AMPA receptors (CX516; Figure 3B). No significant improvement in the primary outcome measure or in secondary measures of language, attention/executive function, or behavior was observed when compared with placebo, possibly due to the potency or dosage of CX516 used (105).

Treatment of Fmr1 KO mice with the mGluR antagonist 2-methyl-6-(phenylethynyl)-pyridine (MPEP) (Figure 3B) resulted in suppression of the audiogenic seizure phenotype (106) and rescue of dendritic spine morphology in the Fmr1 KO mouse (107). Long term use of a similar mGluR5 antagonist, CTEC, in adult animals corrected elevated hippocampal LTD, protein synthesis, spine dysmorphogenesis, overactive ERK and mTOR signaling, and partially corrected macroorchidism (108). These studies paved the way for treatments in humans. Fenobam, used in the past for anxiety treatment (109), was recently tested in adults with FXS (37). Beneficial effects such as reduced anxiety and hyperarousal, improved prepulse inhibition of startle, and better accuracy on a continuous performance task were also reported. Additional trials focused on AFQ056, another mGluR5 antagonist. Intriguingly, in this small trial, improvements in inappropriate speech, stereotypic behavior, and hyperactivity and efficacy have been reported in adults with FXS who have a fully methylated FM allele but not in those with mosaicism (36). Currently, two large multicenter controlled clinical trials with mGluR antagonists (AFQ056, Novartis; RO4917523, Hoffmann-La Roche) are taking place both in adolescents and adults with FXS, followed by an open-label continuation for up to 2 years. Results from these studies are pending $(110,111)$. Another compound, STX107 (SeaSide Therapeutics), acts similarly and will possibly be used in the future for additional clinical trials (112). 
GABAergic system. The GABA receptor system has also been reported as downregulated in FXS, partially due to destabilization of the mRNAs encoding the GABA receptor subunits $(76,80$, 113). Consequently, impaired GABAergic transmission in different brain regions, such as the amygdala, striatum, and cerebral cortex, is believed to contribute to FXS behavioral abnormalities. Pharmacological approaches targeting the GABAergic system have been successfully exploited to correct amygdala-based symptoms in FXS (114). Acamprosate, a molecule used to maintain abstinence from alcohol, is able to block NMDA-R as well as activate $G_{A B A}-R$ and was recently tested in three young adult patients with FXS, who showed global benefit (as rated by the CGI-I scale) and marked communication improvement (115). A large clinical study with ganaxolone, a $\mathrm{GABA}_{\mathrm{A}}$ agonist, is currently ongoing in children and adolescents with FXS between 6 to 17 years of age (116). If efficacy is shown, treatment studies will likely combine ganaxolone with an mGluR5 antagonist to assess synergistic efficacy. Baclofen, a $\mathrm{GABA}_{\mathrm{B}}-\mathrm{R}$ agonist, reduced the susceptibility of Fmr1 KO mice to audiogenic seizures (117). A controlled trial with arbaclofen, the R-isomer of Baclofen (STX069, Seaside Therapeutics Inc.), has undergone a controlled trial in 63 patients with FXS between 6 to 40 years of age with efficacy demonstrated in those with FXS plus ASD and FXS plus low sociability (118-120). As a whole, there are high hopes that some of these drugs will demonstrate efficacy in FXS and eventually become clinically available.

Targeting FMRP downstream targets. Another approach to regulate impaired plasticity associated with FXS is to modulate the levels of dysregulated proteins. With this aim, lithium was shown to decrease the level of glycogen synthase kinase $3 \beta$ (GSK-3 $\beta$ ) linked to mGluR1 signaling and upregulated in FXS (121); used in a pilot trial of 15 patients with FXS, the twomonth treatment was found to have positive effects on behavior and adaptive skills (122).

Matrix metalloproteinase 9 (MMP9) mRNA is among the many putative FMRP target mRNAs with increased translation in FXS (123). Treatment of young mice with minocycline, a broad-spectrum antibiotic, had a dual effect: increased phosphorylation of GluR1 and subsequent membrane insertion of AMPA receptors (124) and lowered MMP9 levels. In FXS mice, upon minocycline treatment, synaptic maturation was rescued, and mice demonstrated improvements in anxiety and in a cognitive task (125). This work stimulated a survey study of families whose children were treated with minocycline, and $70 \%$ noted an improvement in behavior or language (126). In addition, an open trial in adolescent and adult males with FXS demonstrated efficacy in all of the outcome measures (127). Therefore, a controlled trial is being carried out in children with FXS between the ages of 3.5 to 16 years. While the preliminary results are promising, the final results of this study should become available by the end of 2012 (128).

Enriched environment. In addition to pharmacological approaches, an enriched environment has been reported to ameliorate several cellular and behavioral deficits in the mouse model for FXS $(129,130)$. Indeed, cognitive and behavioral therapies in patients, together with educational stimuli, have been beneficial in facilitating the development of self-care and social and adaptive behaviors - all of which greatly enhance the quality of family life within the given contexts (131-135). These studies, as well as the significant placebo effect observed in most drug-based trials, demonstrate the effectiveness of behavioral intervention for children with FXS.

\section{Conclusions and perspectives}

While the molecular roles of FMRP are still being delineated, FMRP is largely established to function in regulating mRNA metabolism in brain. The plethora of putative mRNA targets and several FMRP-interacting proteins with overlapping function could explain the wide and variable physical phenotypes observed in FXS. While observed alterations in excitation/ inhibition balance appear to be the effects of the disease, further studies are necessary to fully address this question. In addition, FMRP is also required for neural stem and progenitor cell proliferation, differentiation, and survival, suggesting additional mechanisms that could explain certain features of the disease (136). Intensive educational interventions in FXS, in addition to these targeted treatments, are important to both strengthen synaptic connections and improve the quality of life for patients. The continued development of new, targeted treatments for FXS, together with existing induced pluripotent stem cell models for FXS (63), give hope that reversing the behavioral and cognitive deficits seen in individuals with this disorder may someday be possible.

\section{Acknowledgments}

This work was supported by grants from VIB, Telethon (GGP10150), Compagnia San Paolo, PRIN 2008, Queen Elisabeth Foundation (NICHD HD036071, HD02274, and NCRR 3UL1 RR024146-04S4), Associazione Italiana Sindrome X Fragile, American National Fragile X, and FRAXA Foundations. We are grateful to Matthew Holt and Tilmann Achsel, and to members of our laboratories for critical reading of the manuscript. We thank Nicholas Rajan for helping with the figures. Due to space constraints, we apologize to our colleagues whose work has not been cited. Further, we limit our discussion to FXS in human and mouse models.

Address correspondence to: Claudia Bagni, Faculty of Medicine, VIB Center for the Biology of Disease Catholic University of Leuven, O\&N I Herestraat 49 - bus 602, 3000 Leuven, Belgium. Phone: 32.16330944; Fax: 39.16330939; E-mail: claudia. bagni@med.kuleuven.be; or: Claudia Bagni, Faculty of Medicine, Department of Biomedicine and Prevention, University of Rome "Tor Vergata", Via Montpellier, 1. 00133 Rome, Italy. Phone: 39.06.72596063; Fax: 39.06.72596058; E-mail: claudia. bagni@uniroma2.it.

\footnotetext{
1. Martin JP, Bell J. A pedigree of mental defect showing sex-linkage. J Neurol Psychiatry. 1943;6(3-4):154-157.

2. Coffee $B$, et al. Incidence of fragile $X$ syndrome by newborn screening for methylated FMR1 DNA. Am J Hum Genet. 2009;85(4):503-514.

3. Hirst MC, Knight SJ, Christodoulou Z, Grewal PK, Fryns JP, Davies KE. Origins of the fragile X syndrome mutation. J Med Genet. 1993;30(8):647-650.
}

4. Fryns JP, Kleczkowska A, Kubien E, Van den Berghe $\mathrm{H}$. Cytogenetic findings in moderate and severe mental retardation. A study of an institutionalized population of 1991 patients. Acta Paediatr Scand Suppl. 1984;313:1-23.

5. Fu Y-H, et al. Variation of the CGG repeat at the fragile $\mathrm{X}$ site results in genetic instability: Resolution of the Sherman paradox. Cell. 1991;67(6):1047-1058.
6. Verkerk AJ, et al. Intragenic probe used for diagnostics in fragile X families. Am J Med Genet. 1992; 43(1-2):192-196.

7. Hagerman R, Au J, Hagerman P. FMR1 premutation and full mutation molecular mechanisms related to autism. J Neurodev Disord. 2011;3(3):211-224.

8. Verkerk AJ, et al. Identification of a gene (FMR-1) containing a CGG repeat coincident with a break- 
point cluster region exhibiting length variation in fragile X syndrome. Cell. 1991;65(5):905-914.

9. Oberle I, et al. Instability of a 550-base pair DNA segment and abnormal methylation in fragile $\mathrm{X}$ syndrome. Science. 1991;252(5009):1097-1102.

10. Fernandez-Carvajal I, Lopez Posadas B, Pan R, Raske C, Hagerman PJ, Tassone F. Expansion of an FMR1 grey-zone allele to a full mutation in two generations. J Mol Diagn. 2009;11(4):306-310.

11. Nolin SL, et al. Expansion of the fragile X CGG repeat in females with premutation or intermediate alleles. Am J Hum Genet. 2003;72(2):454-464.

12. Yrigollen CM, et al. AGG interruptions within the maternal FMR1 gene reduce the risk of offspring with fragile X syndrome. Genet Med. 2012; 14(8):729-736

13. Pietrobono R, et al. Molecular dissection of the events leading to inactivation of the FMR1 gene. Hum Mol Genet. 2005;14(2):267-277.

14. Pieretti M, et al. Absence of expression of the FMR-1 gene in fragile X syndrome. Cell. 1991;66(4):817-822.

15. Naumann A, Hochstein N, Weber S, Fanning E, Doerfler W. A distinct DNA-methylation boundary in the $5^{\prime}$ - upstream sequence of the FMR1 promoter binds nuclear proteins and is lost in fragile X syndrome. Am J Hum Genet. 2009;85(5):606-616.

16. Malter HE, et al. Characterization of the full fragile $\mathrm{X}$ syndrome mutation in fetal gametes. Nat Genet. 1997;15(2):165-169.

17. Sutcliffe JS, et al. DNA methylation represses FMR-1 transcription in fragile X syndrome. Hum Mol Genet. 1992;1(6):397-400.

18. Tabolacci E, Moscato U, Zalfa F, Bagni C, Chiurazzi P, Neri G. Epigenetic analysis reveals a euchromatic configuration in the FMR1 unmethylated full mutations. Eur J Hum Genet. 2008;16(12):1487-1498.

19. Kumari D, Usdin K. Interaction of the transcription factors USF1, USF2, and (alpha)-PAL/Nrf-1 with the FMR1 promoter. I Biol Chem. 2001; 276(6):4357-4364

20. Coffee B, Zhang F, Warren ST, Reines D. Acetylated histones are associated with FMR1 in normal but not fragile X-syndrome cells. Nat Genet. 1999;22(1):98-101.

21. Tassone F, Hagerman RJ, Loesch DZ, Lachiewicz A, Taylor AK, Hagerman PJ. Fragile X males with unmethylated, full mutation trinucleotide repeat expansions have elevated levels of FMR1 messenger RNA. Am J Med Genet. 2000;94(3):232-236.

22. Smeets HJ, et al. Normal phenotype in two brothers with a full FMR1 mutation. Hum Mol Genet. 1995;4(11):2103-2108

23. Bailey DB Jr, Raspa M, Bishop E, Holiday D. No change in the age of diagnosis for fragile $\mathrm{x}$ syndrome: findings from a national parent survey. Pediatrics. 2009;124(2):527-533.

24. Cordeiro L, Ballinger E, Hagerman R, Hessl D. Clinical assessment of DSM-IV anxiety disorders in fragile X syndrome: prevalence and characterization. J Neurodev Disord. 2011;3(1):57-67.

25. Sullivan K, et al. ADHD symptoms in children with FXS. Am J Med Genet A. 2006;140(21):2275-2288.

26. Irwin $S A$, et al. Abnormal dendritic spine characteristics in the temporal and visual cortices of patients with fragile- $X$ syndrome: a quantitative examination. Am J Med Genet. 2001;98(2):161-167.

27. Carrasco M. [Informing members of families affected by fragile $\mathrm{X}$ syndrome of this diagnosis]. Rev Neurol. 2001;33(suppl 1):S37-S41.

28. Garcia-Arocena D, Hagerman PJ. Advances in understanding the molecular basis of FXTAS. Hum Mol Genet. 2010;19(R1):R83-R89.

29. Cornish KM, et al. The emerging fragile X premutation phenotype: Evidence from the domain of social cognition. Brain Cogn. 2005;57(1):53-60.

30. Bacalman S, et al. Psychiatric phenotype of the fragile $\mathrm{X}$-associated tremor/ataxia syndrome (FXTAS) in males: newly described fronto-subcor- tical dementia. J Clin Psychiatry. 2006;67(1):87-94

31 . Chonchaiya W, et al. Increased prevalence of seizures in boys who were probands with the FMR1 premutation and co-morbid autism spectrum disorder. Hum Genet. 2012;131(4):581-589.

32. Allingham-Hawkins DJ, et al. Fragile X premutation is a significant risk factor for premature ovarian failure: the International Collaborative POF in Fragile X study-preliminary data. Am J Med Genet. 1999;83(4):322-325.

33. Tassone F, et al. Newborn screening in fragile $X$ syndrome: prevalence and allele distribution of the FMR1 gene. Paper presented at: American College of Medical Genetics Annual Clinical Genetics Meeting; July 26, 2012; Charlotte, North Carolina, USA http://www.fragilex.org/community/internationalfragile-x-conference/miami2012/agenda/. Accessed October 19, 2012

34. Fernandez-Carvajal I, Walichiewicz P, Xiaosen X, Pan R, Hagerman PJ, Tassone F. Screening for expanded alleles of the FMR1 gene in blood spots from newborn males in a Spanish population. J Mol Diagn. 2009;11(4):324-329.

35. Dombrowski C, Levesque ML, Morel ML, Rouillard P, Morgan K, Rousseau F. Premutation and intermediate-size FMR1 alleles in 10572 males from the general population: loss of an AGG interruption is a late event in the generation of fragile $\mathrm{X}$ syndrome alleles. Hum Mol Genet. 2002;11(4):371-378.

36. Jacquemont $S$, et al. Epigenetic modification of the FMR1 gene in fragile $\mathrm{X}$ syndrome is associated with differential response to the mGluR5 antagonist AFQ056. Sci Transl Med. 2011;3(64):64ra61.

37. Berry-Kravis E, et al. A pilot open label, single dose trial of fenobam in adults with fragile $\mathrm{X}$ syndrome. JMed Genet. 2009;46(4):266-271.

38. Tassone F, Pan R, Amiri K, Taylor AK, Hagerman PJ. A rapid polymerase chain reaction-based screening method for identification of all expanded alleles of the fragile X (FMR1) gene in newborn and high-risk populations. J Mol Diagn. 2008;10(1):43-49.

39. Filipovic-Sadic S, et al. A novel FMR1 PCR method for the routine detection of low abundance expanded alleles and full mutations in fragile $\mathrm{X}$ syndrome. Clin Chem. 2010;56(3):399-408.

40. Hantash FM. Fragile X syndrome: is now the time for population screening? MLO Med Lab Obs. 2010;42(5):20, 22

41. Lyon E, et al. A simple, high-throughput assay for Fragile X expanded alleles using triple repeat primed PCR and capillary electrophoresis. J Mol Diagn. 2010;12(4):505-511.

42. Godler DE, Slater HR, Amor D, Loesch DZ. Methylation analysis of fragile X-related epigenetic elements may provide a suitable newborn screening test for fragile X syndrome. Genet Med. 2010; 12(9):595.

43. Coffee B. Commentary on population screening for fragile X syndrome. Genet Med. 2010;12(7):411-412.

44. Xuncla M, et al. Fragile X syndrome prenatal diagnosis: parental attitudes and reproductive responses. Reprod Biomed Online. 2010;21(4):560-565.

45. McDuffie A, et al. Autism spectrum disorder in children and adolescents with fragile X syndrome: within-syndrome differences and age-related changes. Am J Intellect Dev Disabil. 2010; 115(4):307-326.

46. Hatton DD, et al. Autistic behavior in children with fragile X syndrome: prevalence, stability, and the impact of FMRP. Am J Med Genet A. 2006; 140A(17):1804-1813.

47. Berry-Kravis E. Epilepsy in fragile X syndrome. Dev Med Child Neurol. 2002;44(11):724-728.

48. Garcia-Nonell C, et al. Secondary medical diagnosis in fragile $\mathrm{X}$ syndrome with and without autism spectrum disorder. Am J Med Genet A. 2008; 146A(15):1911-1916.
49. Meguid NA, et al. Cognition and lobar morphology in full mutation boys with fragile $\mathrm{X}$ syndrome. Brain Cogn. 2012;78(1):74-84.

50. Dawson G, Hessl D, Frey K. Social influences on early-developing biological and behavioral systems related to risk for affective disorder. In: Cicchetti D, Tucker, eds. Special Issue of Development and Psychopathology on "Neural plasticity, sensitive periods and psychopathology." 1995;6:759-780.

51. Dawson G, et al. Randomized, controlled trial of an intervention for toddlers with autism: the Early Start Denver Model. Pediatrics. 2010; 125(1):e17-e23.

52. Napoli I, et al. The fragile X syndrome protein represses activity-dependent translation through CYFIP1, a new 4E-BP. Cell. 2008;134(6):1042-1054.

53. Nishimura Y, et al. Genome-wide expression profiling of lymphoblastoid cell lines distinguishes different forms of autism and reveals shared pathways. Hum Mol Genet. 2007;16(14):1682-1698.

54. van der Zwaag B, et al. A co-segregating microduplication of chromosome $15 \mathrm{q} 11.2$ pinpoints two risk genes for autism spectrum disorder. Am J Med Genet B Neuropsychiatr Genet. 2010;153B(4):960-966.

55. Leblond CS, et al. Genetic and functional analyses of SHANK2 mutations suggest a multiple hit model of autism spectrum disorders. PLoS Genet. 2012;8(2):e1002521.

56. Schellenberg GD, et al. Evidence for multiple loci from a genome scan of autism kindreds. Mol Psychiatry. 2006;11(11):1049-1060, 1979.

57. Neves-Pereira M, et al. Deregulation of EIF4E: a novel mechanism for autism. J Med Genet. 2009;46(11):759-765.

58. Darnell JC, et al. FMRP stalls ribosomal translocation on mRNAs linked to synaptic function and autism. Cell. 2011;146(2):247-261.

59. Eberhart DE, Malter HE, Feng Y, Warren ST. The fragile $\mathrm{X}$ mental retardation protein is a ribonucleoprotein containing both nuclear localization and nuclear export signals. Hum Mol Genet. 1996;5(8):1083-1091.

60. Sittler A, Devys D, Weber C, Mandel JL. Alternative splicing of exon 14 determines nuclear or cytoplasmic localisation of fmr1 protein isoforms. Hum Mol Genet. 1996;5(1):95-102.

61. Bagni C, Greenough WT. From mRNP trafficking to spine dysmorphogenesis: the roots of fragile $\mathrm{X}$ syndrome. Nat Rev Neurosci. 2005;6(5):376-387.

62. De Rubeis S, Fernandez E, Buzzi A, Di Marino D, Bagni C. Molecular and Cellular Aspects of Mental Retardation in the Fragile X Syndrome: From Gene Mutation/s to Spine Dysmorphogenesis. Adv Exp Med Biol. 2012;970:517-551.

63. Wang T, Bray SM, Warren ST. New perspectives on the biology of fragile X syndrome. Curr Opin Genet Dev. 2012;22(3):256-263.

64. Anderson P, Kedersha N. RNA granules. J Cell Biol. 2006;172(6):803-808.

65. Brown V, et al. Microarray identification of FMRP-associated brain mRNAs and altered mRNA translational profiles in fragile $\mathrm{X}$ syndrome. Cell. 2001;107(4):477-487.

66. Chen L, Yun SW, Seto J, Liu W, Toth M. The fragile $\mathrm{X}$ mental retardation protein binds and regulates a novel class of mRNAs containing $U$ rich target sequences. Neuroscience. 2003;120(4):1005-1017.

67. Miyashiro KY, et al. RNA cargoes associating with FMRP reveal deficits in cellular functioning in Fmr1 null mice. Neuron. 2003;37(3):417-431.

68. Bakker CE, et al. FMR1 knockout mice: A model to study fragile X mental retardation. Cell. 1994; 78(1):23-33.

69. Zalfa F, et al. The fragile $\mathrm{X}$ syndrome protein FMRP associates with BC1 RNA and regulates the translation of specific mRNAs at synapses. Cell. 2003;112(3):317-327.

70. Zalfa F, et al. A new function for the fragile X men- 
tal retardation protein in regulation of PSD-95 mRNA stability. Nat Neurosci. 2007;10(5):578-587.

71. Muddashetty RS, Kelic S, Gross C, Xu M, Bassell GJ. Dysregulated metabotropic glutamate receptor-dependent translation of AMPA receptor and postsynaptic density-95 mRNAs at synapses in a mouse model of fragile X syndrome. J Neurosci. 2007;27(20):5338-5348.

72. Narayanan U, et al. S6K1 phosphorylates and regulates fragile $\mathrm{X}$ mental retardation protein (FMRP) with the neuronal protein synthesis-dependent mammalian target of rapamycin (mTOR) signaling cascade. J Biol Chem. 2008;283(27):18478-18482.

73. Westmark CJ, Malter JS. FMRP mediates mGluR5-dependent translation of amyloid precursor protein. PLoS Biol. 2007;5(3):e52.

74. Lacoux C, et al. BC1-FMRP interaction is modulated by 2 '-O-methylation: RNA-binding activity of the tudor domain and translational regulation at synapses. Nucleic Acids Res. 2012;40(9):4086-4096.

75. Bear MF, Huber KM, Warren ST. The mGluR theory of fragile $\mathrm{X}$ mental retardation. Trends Neurosci. 2004;27(7):370-377.

76. Centonze D, et al. Abnormal striatal GABA transmission in the mouse model for the fragile $\mathrm{X}$ syndrome. Biol Psychiatry. 2008;63(10):963-973.

77. Gatto CL, Broadie K. Genetic controls balancing excitatory and inhibitory synaptogenesis in neurodevelopmental disorder models. Front Synaptic Neurosci. 2010;2:4.

78. Huber KM, Gallagher SM, Warren ST, Bear MF. Altered synaptic plasticity in a mouse model of fragile X mental retardation. Proc Natl Acad Sci U S A. 2002;99(11):7746-7750.

79. Nakamoto M, Nalavadi V, Epstein MP, Narayanan U, Bassell GJ, Warren ST. Fragile $\mathrm{X}$ mental retardation protein deficiency leads to excessive mGluR5-dependent internalization of AMPA receptors. Proc Natl Acad Sci U S A. 2007;104(39):15537-15542.

80. Curia G, Papouin T, Seguela P, Avoli M. Downregulation of tonic GABAergic inhibition in a mouse model of fragile X syndrome. Cereb Cortex. 2009;19(7):1515-1520

81. Shang Y, Wang H, Mercaldo V, Li X, Chen T, Zhuo $\mathrm{M}$. Fragile $\mathrm{X}$ mental retardation protein is required for chemically-induced long-term potentiation of the hippocampus in adult mice. J Neurochem. 2009;111(3):635-646.

82. Suvrathan A, Hoeffer CA, Wong H, Klann E, Chattarji S. Characterization and reversal of synaptic defects in the amygdala in a mouse model of fragile X syndrome. Proc Natl Acad Sci U S A. 2010;107(25):11591-11596.

83. Eadie BD, Cushman J, Kannangara TS, Fanselow MS, Christie BR. NMDA receptor hypofunction in the dentate gyrus and impaired context discrimination in adult Fmr1 knockout mice. Hippocampus. 2012;22(2):241-254.

84. Yun SH, Trommer BL. Fragile X mice: reduced long-term potentiation and N-Methyl-D-Aspartate receptor-mediated neurotransmission in dentate gyrus. J Neurosci Res. 2011;89(2):176-182.

85. Louhivuori $\mathrm{V}$, et al. BDNF and TrkB in neuronal differentiation of Fmr1-knockout mouse. Neurobiol Dis. 2011;41(2):469-480.

86. Nalavadi VC, Muddashetty RS, Gross C, Bassell GJ. Dephosphorylation-induced ubiquitination and degradation of FMRP in dendrites: a role in immediate early mGluR-stimulated translation. J Neurosci. 2012;32(8):2582-2587.

87. Hoeffer CA, et al. Altered mTOR signaling and enhanced CYFIP2 expression levels in subjects with fragile X syndrome. Genes Brain Behav. 2012; 11(3):332-341.

88. Kim SH, Markham JA, Weiler IJ, Greenough WT. Aberrant early-phase ERK inactivation impedes neuronal function in fragile X syndrome. Proc Natl
Acad Sci U S A. 2008;105(11):4429-4434.

89. Sharma A, et al. Dysregulation of mTOR signaling in fragile X syndrome. J Neurosci. 2010;30(2):694-702.

90. Dolen $\mathrm{G}$, et al. Correction of fragile X syndrome in mice. Neuron. 2007;56(6):955-962.

91. Westmark CJ, et al. Reversal of fragile X phenotypes by manipulation of AbetaPP/Abeta levels in Fmr1KO mice. PLoS One. 2011;6(10):e26549.

92. Auerbach BD, Osterweil EK, Bear MF. Mutations causing syndromic autism define an axis of synaptic pathophysiology. Nature. 2011;480(7375):63-68.

93. Hayashi ML, et al. Inhibition of p21-activated kinase rescues symptoms of fragile $\mathrm{X}$ syndrome in mice. Proc Natl Acad Sci U S A. 2007;104(27):11489-11494.

94. Goebel-Goody SM, Wilson-Wallis ED, Royston S, Tagliatela SM, Naegele JR, Lombroso PJ. Genetic manipulation of STEP reverses behavioral abnormalities in a fragile $\mathrm{X}$ syndrome mouse model. Genes Brain Behav. 2012;11(5):586-600.

95. Chiurazzi P, Pomponi MG, Willemsen R, Oostra $\mathrm{BA}$, Neri G. In vitro reactivation of the FMR1 gene involved in fragile X syndrome. Hum Mol Genet. 1998;7(1):109-113.

96. Chiurazzi P, Pomponi MG, Pietrobono R, Bakker CE, Neri G, Oostra BA. Synergistic effect of histone hyperacetylation and DNA demethylation in the reactivation of the FMR1 gene. Hum Mol Genet. 1999;8(12):2317-2323.

97. Tabolacci E, Pietrobono R, Moscato U, Oostra BA, Chiurazzi P, Neri G. Differential epigenetic modifications in the FMR1 gene of the fragile $\mathrm{X}$ syndrome after reactivating pharmacological treatments. Eur J Hum Genet. 2005;13(5):641-648.

98. Pomponi MG, Neri G. Butyrate and acetyl-carnitine inhibit the cytogenetic expression of the fragile $\mathrm{X}$ in vitro. Am J Med Genet. 1994;51(4):447-450.

99. Torrioli MG, et al. Double-blind, placebo-controlled study of L-acetylcarnitine for the treatment of hyperactive behavior in fragile X syndrome. Am J Med Genet. 1999;87(4):366-368.

100. Torrioli MG, et al. A double-blind, parallel, multicenter comparison of L-acetylcarnitine with placebo on the attention deficit hyperactivity disorder in fragile X syndrome boys. Am J Med Genet A. 2008;146(7):803-812.

101. Phiel CJ, Zhang F, Huang EY, Guenther MG, Lazar MA, Klein PS. Histone deacetylase is a direct target of valproic acid, a potent anticonvulsant, mood stabilizer, and teratogen. J Biol Chem. 2001;276(39):36734-36741.

102. Detich N, Bovenzi V, Szyf M. Valproate induces replication-independent active DNA demethylation. J Biol Chem . 2003;278(30):27586-27592.

103. Tabolacci E, et al. Modest reactivation of the mutant FMR1 gene by valproic acid is accompanied by histone modifications but not DNA demethylation. Pharmacogenet Genomics. 2008;18(8):738-741.

104. Torrioli $\mathrm{M}$, et al. Treatment with valproic acid ameliorates $\mathrm{ADHD}$ symptoms in fragile $\mathrm{X}$ syndrome boys. Am J Med Genet A. 2010;152A(6):1420-1427.

105. Berry-Kravis E, et al. Effect of CX516, an AMPAmodulating compound, on cognition and behavior in fragile X syndrome: a controlled trial. J Child Adolesc Psychopharmacol. 2006;16(5):525-540.

106. Yan QJ, Rammal M, Tranfaglia M, Bauchwitz RP. Suppression of two major Fragile X Syndrome mouse model phenotypes by the mGluR5 antagonist MPEP. Neuropharmacology. 2005;49(7):1053-1066.

107. Su T, et al. Early continuous inhibition of group 1 mGlu signaling partially rescues dendritic spine abnormalities in the Fmr1 knockout mouse model for fragile X syndrome. Psychopharmacology (Berl). 2011;215(2):291-300

108. Michalon A, et al. Chronic Pharmacological mGlu5 Inhibition Corrects Fragile X in Adult Mice. Newron. 2012;74(1):49-56.

109.Pecknold JC, McClure DJ, Appeltauer L, Wrzesinski $\mathrm{L}$, Allan T. Treatment of anxiety using fenobam (a nonbenzodiazepine) in a double-blind standard (diazepam) placebo-controlled study. J Clin Psychopharmacol. 1982;2(2):129-133

110.Novartis. Efficacy, Safety and Tolerability of AFQ056 in Fragile X Patients. NIH Web site. http://clinicaltrials.gov/ct2/show/NCT00718341. Updated May 5, 2010. Updated October 19, 2012.

111. Hoffmann-La Roche. A Study With RO4917523 in Patients With Fragile X Syndrome. NIH Web site. http://clinicaltrials.gov/ct2/show/ NCT01015430?term=RO4917523\&rank=4. Updated December 5, 2011. Accessed October 19, 2012.

112. Seaside Therapeutics, Inc. A Single-Dose Study in Normal Volunteers to Assess the Safety, Tolerability and Pharmacokinetics of STX107. NIH Web site. http://clinicaltrials.gov/ct2/show/ NCT00965432?term=STX107\&rank=2. Updated February 5, 2010. Accessed October 19, 2012.

113. D'Hulst C, et al. Decreased expression of the GABAA receptor in fragile X syndrome. Brain Res. 2006;1121(1):238-245.

114. Olmos-Serrano JL, Paluszkiewicz SM, Martin BS, Kaufmann WE, Corbin JG, Huntsman MM. Defective GABAergic neurotransmission and pharmacological rescue of neuronal hyperexcitability in the amygdala in a mouse model of fragile $\mathrm{X}$ syndrome. J Neurosci. 2010;30(29):9929-9938.

115. Erickson CA, Mullett JE, McDougle CJ. Brief report: acamprosate in fragile $\mathrm{X}$ syndrome. J Autism Dev Disord. 2010;40(11):1412-1416.

116. Hagerman RJ, Hessl D, Rogawski M. A Controlled Double-Blind Cross-over Trial of Ganaxolone in Children with Fragile X Syndrome. Marinus Web site. http://www.marinuspharma.com/collaborators. html. Accessed October 19, 2012.

117. Pacey LK, Heximer SP, Hampson DR. Increased $\mathrm{GABA}(\mathrm{B})$ receptor-mediated signaling reduces the susceptibility of fragile $\mathrm{X}$ knockout mice to audiogenic seizures. Mol Pharmacol. 2009;76(1):18-24.

118. Berry-Kravis EM, et al. Effects of STX209 (arbaclofen) on neurobehavioral function in children and adults with fragile X syndrome: A randomized, controlled, Phase 2 trial. Sci Transl Med. 2012;4(152):152ra127.

119.Seaside Therapeutics, Inc. Safety, Tolerability and Efficacy Study of STX209 in Subjects With Fragile X Syndrome. NIH Web site. http://clinicaltrials.gov/ ct $2 /$ show/NCT00788073?term =berry-kravis $\&$ rank=3. Updated September 28, 2012. Accessed October 19, 2012.

120. Seaside Therapeutics, Inc. A Fixed-Dose Study of the Efficacy, Safety, and Tolerability of STX209 (Arbaclofen) Administered for the Treatment of Social Withdrawal in Children With Fragile X Syndrome (Harbor-C). NIH Web site. http:// clinicaltrials.gov/ct2/show/NCT01325220?term= baclofen+and+fragile+x\&rank $=1$. Updated October 10, 2012. Accessed October 19, 2012.

121. Min WW, et al. Elevated glycogen synthase kinase-3 activity in fragile $\mathrm{X}$ mice: key metabolic regulator with evidence for treatment potential. Neuropharmacology. 2009;56(2):463-472.

122. Berry-Kravis E, et al. Open-label treatment trial of lithium to target the underlying defect in fragile $\mathrm{X}$ syndrome. J Dev Behav Pediatr. 2008;29(4):293-302.

123. Bilousova TV, Rusakov DA, Ethell DW, Ethell IM. Matrix metalloproteinase-7 disrupts dendritic spines in hippocampal neurons through NMDA receptor activation. J Neurochem. 2006;97(1):44-56.

124.Imbesi M, Uz T, Manev R, Sharma RP, Manev H. Minocycline increases phosphorylation and membrane insertion of neuronal GluR1 receptors. Newrosci Lett. 2008;447(2-3):134-137.

125. Bilousova TV, et al. Minocycline promotes dendritic spine maturation and improves behavioural performance in the fragile X mouse model. J Med Genet. 2009;46(2):94-102.

126. Utari A, et al. Side effects of minocycline treatment in patients with fragile $\mathrm{X}$ syndrome and explo- 
ration of outcome measures. Am J Intellect Dev Disabil. 2010;115(5):433-443.

127. Paribello C. Open label add on treatment trial of minocycline in patients with fragile $\mathrm{X}$ syndrome. BMC Neurol. 2010;10:91.

128.Hagerman RJ. Trial of Minocycline to Treat Children With Fragile X Syndrome. NIH Web site. http://clinicaltrials.gov/ct2/show/ NCT01053156?term $=$ minocycline + and + fragile x\&rank=1. Updated April 10, 2012. Accessed October 19, 2012.

129. Restivo L, et al. Enriched environment promotes behavioral and morphological recovery in a mouse model for the fragile X syndrome. Proc Natl Acad Sci US A. 2005;102(32):11557-11562.

130. Meredith RM, Holmgren CD, Weidum M, Burna- shev N, Mansvelder HD. Increased threshold for spike-timing-dependent plasticity is caused by unreliable calcium signaling in mice lacking fragile X gene FMR1. Neuron. 2007;54(4):627-638

131. Moskowitz LJ, Carr EG, Durand VM. Behavioral intervention for problem behavior in children with fragile X syndrome. Am J Intellect Dev Disabil. 2011;116(6):457-478.

132.Turk J. Fragile X syndrome: lifespan developmental implications for those without as well as with intellectual disability. Curr Opin Psychiatry. 2011;24(5):387-397.

133. Braden M. Classroom adaptations: good practice and work habits. In: Dew-Hughes D, ed. Educating Children With Fragile X Syndrome: A Miltiprofessional View. New York, New York, USA: Routledge-
Falmer; 2004:83-96.

134.Dyer-Friedman J, et al. Genetic and environmental influences on the cognitive outcomes of children with fragile X syndrome. J Am Acad Child Adolesc Psychiatry. 2002;41(3):237-244.

135. Hessl D, et al. The influence of environmental and genetic factors on behavior problems and autistic symptoms in boys and girls with fragile $\mathrm{X}$ syndrome. Pediatrics. 2001;108(5):E88.

136. Callan MA, Zarnescu DC. Heads-up: new roles for the fragile $\mathrm{X}$ mental retardation protein in neural stem and progenitor cells. Genesis. 2011;49(6):424-440.

137. Narayanan U, et al. FMRP phosphorylation reveals an immediate-early signaling pathway triggered by group I mGluR and mediated by PP2A. J Neurosci. 2007;27(52):14349-14357. 